\title{
Impact of Outdoor Advertising on Safety of Highway Users in Lagos and Abeokuta Metropolis
}

\author{
Ajasa, Ayoola Olalekan ${ }^{1 *} \quad$ Edomi, Ovie $^{1} \quad$ Adeniji, Oluwatomi Caleb $^{2}$ \\ 1. Department of Mass Communication, Babcock University, Ilishan-Remo, Ogun State, Nigeria \\ 2. Bowen University, Iwo, Osun State
}

\begin{abstract}
This study assessed the impact of Outdoor advertising on the safety of highway users. It was underpinned by the Klapper's Phenomenistic Theory. Data used for meeting the study objectives were gathered with the questionnaire and analysed quantitatively. The study found out that Outdoor advertising had no negative influence on the safety of highway users. The study also concluded that Outdoor advertising, rather than constituting an environmental nuisance, beautify the environment. The study recommends that advertisers should leverage on the uniqueness of Outdoor advertising to advertise their products and services; road users, on the other hand, should be focused while on the highway and avoid billboard distraction. Also, regulatory authorities should enforce compliance to rules and regulations and ensure the upholding of best practices by the various practitioners and stakeholders in the industry for the benefits of all and sundry.
\end{abstract}

Keywords: Outdoor advertising, Distraction, Billboards, Safety, Highway users

DOI: 10.7176/NMMC/79-05

Publication date: April $30^{\text {th }} 2019$

\section{Introduction}

Practitioners have identified advertising as a powerful sales and marketing technique. Its importance and contribution to the overall marketing of a product cannot be over-emphasized. Advertising keeps the business going and sells the product before the actual purchase of that product (Daramola, 2010). The advertisement of a product reached the audience in the confines of their private rooms or in their offices while reading a particular newspaper or magazine, listening to a favourite radio station, television, and new media or on the highways (Osunbiyi, 1999). These days advertising has penetrated all spheres of human life, breaking into people's privacy; no thanks to the latest technology.

There are various definitions of advertising as there are advertising executives and each definition is unique in its own way. The American Marketing Association (AMA) posits that advertising is any paid form of nonpersonal presentation or promotion of goods and services by an identified sponsor (Kotler, 1990). In the same vein, the Advertising Practitioners' Council of Nigeria (APCON) describes advertising as a form of persuasive communication through the media about products, services or ideas paid for by an identifiable sponsor (Daramola, 2010). The British Institute of Practitioners in Advertising (BIPA) asserts that "advertising presents the most persuasive possible selling message to the right prospects at the lowest possible cost" (Jefkins, 1991). For the purpose of this research, the definition of AMA was adopted as the working definition.

There are various forms of media for advertising. Media, according to Wirsig (1987 p.87), are "channels or vehicles of communication that any advertising message from the advertiser gets to larger groups of prospective consumers". Furthermore, media are channels through which advertisers can reach potential buyers at the ideal place and time. It is through the media that the gap between the producer and consumer is being bridged.

To a media buyer, there is a seemingly endless variety of advertising media ranging from electronic, print, internet and Outdoor media. Of all the above media, the area of focus of this study is Outdoor media. Falling into this category are all forms of advertising that provide exposure out-of-doors. To be precise, any form of an advertising message that is seen Outdoor can be considered as Outdoor advertising. Among such are billboards, posters, walls, bus, rail, and mobile and electronic billboards.

According to Osunbiyi (1999), Outdoor advertising is a form of advertising which is remarkable for its uniqueness in that it does not circulate around the market but the market circulates around it with little or no audience selectivity. This definition became quite relevant as this research examined the "impact" of Outdoor advertising on the safety of highway users. In the same vein, Virginia (2014) submits that roadside advertising for example billboards are used for advertisement of various products and services and are meant to attract passersby's attention to the message or information conveyed by the billboards.

Outdoor advertising is one of the oldest media of advertising in the world. Roadside advertising has one purpose and one purpose only: to distract drivers (Cottingham, 2017). In ancient times, stones and wooden signs were used as Outdoor communication channels (Wright, 1995). Generally speaking, Outdoor advertising includes all means of non-personal communication used to expose advertisements to specific audiences outside their homes and other buildings. Historically, Outdoor advertising, according to Aroloye (1997) was viewed as a lesser medium which advertisers gave little attention. For a long time, Outdoor played second, third or even 
fourth fiddle to other mass media such as TV, radio, newspaper and magazine. In recent times, Outdoor has not only become a prime advertising medium but assumed a supreme status. It is now being used as a primary and sometimes even as a solo medium of advertising in Nigeria (Akinbobola, 1996).

Outdoor Advertising Association of America (OAAA), (2013) corroborates the assertion of Akinbobola, (1996) on the new status of outdoor advertising. He maintains that roadside advertising billboard can be either static or digital. Static billboards show the same message for an extended period of time (typically days). They are the traditional type of Outdoor advertising and the most commonly used type of advertising billboards in the United States. The Digital Billboards (DBBs) were introduced in the recent years and utilize light-emitting diode (LED) technology to show multiple messages one after another that are updated using computer input, because DBBs flash images every four to ten seconds (Copeland, 2010), a single board can advertise too far more clients than a traditional board, making them attractive advertisement options. Thus, despite the fact that DBBs are initially more expensive to build compared to their static counterparts, over time, they prove to be cost-effective. While static billboards are still dominant, digital billboards are a fast-growing sector of the Outdoor advertising market (OAAA, 2013).

The increased number and sophistication of DBBs and other forms of Outdoor advertising raise questions about their potential impact on traffic safety and other highway users. As a medium, Outdoor advertising purposely encourages drivers to shift their attention away from the driving task (Sisiopiku, Mozahidul, Wittig, Welburn and Despina, (2014). Moreover, digital billboards brightness may be especially problematic at night and may affect the driver's ability to observe changes in the surrounding environment such as brake lights or signal changes. Also, frequently changing images may compel more glances, and sequential messages may hold drivers' gazes longer until the entire message is read. Lastly, targeted messages that promote interactivity with the driver are particularly troublesome as they are hypothesized to be distracting to the driver (Sisiopiku et al, 2014). It is a fact that Outdoor advertising, when compared to other forms of advertising media, has certain strengths which include dominant illustration, brief or short messages, Twenty-four-hour exposure, long life span, geographical flexibility among others. It is also a truism that it comes with some certain weaknesses some of which are relevant to this study; these include reduced or poor visibility of motorist, distraction, habitat for miscreants and environmental nuisance. In their submission, Oviedo-Trespalacios, Truelove, Watson \& Hinton, J. (2019) identified drivers' inattention and distraction as two of the most critical factors for road safety worldwide. While roadside advertising is often identified as a potential source of distraction, it has received less attention compared to other types of distractions such as texting or calling while driving. In view of the above, this study examined the impact of Outdoor advertising on the safety of highway users.

\subsection{Problem Statement}

Several studies have established the relationship between Outdoor advertising, driver distraction and traffic safety. They provide some evidence for a correlation between advertising billboards and increased drivers' distraction. According to Vlakveld and Helman (2019 p.6) "Roadside advertising is, by its nature, designed to capture the attention of road users; because humans have limited attentional resources it is therefore possible that such advertisements could hamper the safe execution of the driving task." However, local conditions, environmental factors and other factors that may play a role in the continuous rise in road accidents on the highway are not accounted for. Overall, the outcomes of earlier research studies have resulted in somewhat contradictory conclusions, indicating a need for further research. Furthermore, earlier studies have looked at the distractive effects of billboards on the general population; however, little research has been done on the safety of highway users in relations to Outdoor advertising. To bridge existing knowledge gaps, this study investigated the potential relationship between Outdoor advertising and safety of the highway users.

\subsection{Research Questions}

1. Is Outdoor advertising a distraction to highway users?

2. Does Outdoor advertising impact negatively on the safety of highway users?

3. Does Outdoor advertising constitute an environmental nuisance?

\subsection{Scope of the Study}

This study investigated the impact of Outdoor advertising on the safety of highway users in Lagos and Abeokuta metropolis, Nigeria.

\section{Review of Literature}

\subsection{Outdoor Advertising and its Development in Nigeria}

The growth of the Outdoor advertising medium in the last few years, especially the high increase in the number of boarding in our cities has made it imperative for more imaginative use of Outdoor advertising as an effective medium of advertising. Perhaps a cursory look at the history of this important medium in Nigeria would help us 
to appreciate what has led to the challenges that we have today in Outdoor advertising industry. For better understanding, according to Akinbobola (1996), he divided the period under consideration into three. First, the period before indigenization which he called the glorious yesterday, secondly, the period after indigenization which he called the Confused Period and the last period which he called Glorious Tomorrow.

2.1.1 The Glorious Yesterday

The researcher hates to admit that the best to happen in Outdoor advertising in Nigeria had happened in the 1960s and early 80's when the expatriates owned all advertising outfits or were still in control shortly after indigenization. This was when giant institutions such as West African Publicity Company, Afromedia, Graham Gillies, United African Company, Research Bureau Nigeria Limited (RBNL) Gilbertson, Greenland Advertising, Nigerian Railway Corporation (RWC), Wilmer Publicity, ROD Publicity, OAAN were dominating the scene of Advertising. Akinbobola further identified the characters of Outdoor advertising than as:

Hoardings were few but were strategically located and well-spaced from one another; each billboard was solos and therefore very impactful. Many billboards were illuminated. There were bulletin billboards with neon light to add to the aesthetics of such heavy traffic junctions as Iddo, Idumota, Ijora etc, all in Lagos. Similar sites also existed in major cities across the country. All these neon signs and illuminated boards erected on highways such as the famous Gold-Leaf and Varsity cigarette billboards were safe from vandals. During this period, neon signs adorned several rooftops in Lagos and other cities providing a picture square view at night.

There was a poster -16 sheet and 40 sheet sizes that were well located and maintained by the contractors. The medium planner did not have problems buying hoarding because the contractors kept strictly to the ethics of the industry. The two main contractors during the time were Afromedia and Nigerian Railway Advertising Services which were being run by expatriates, who apparently were practising according to the rules of the Outdoor advertising industry in the UK. A couple of indigenous contractors such as Gilbertson Publicity and Wilmer Publicity restricted themselves to small regions and operated diligently under the watchful eyes of the agency and advertisers branch offices. Two of the largest national users of Outdoor and advertising than were the Nigerian Tobacco Company (NTC) and Cadbury.

2.1.2 The Confused Period

The indigenization policy was hailed because it allowed Nigerians to directly control a large proportional of our economy. However, it should be admitted that many professionals were ill-prepared for the take-over of responsibility from the expatriates. In the Outdoor advertising industry, the first sign of the departure of the expatriates was the disappearance from our highways of the beautiful and imposing billboard, (Akinbobola, 1996). These were soon replaced by the plywood/wood structures mainly in the 40-sheet and 16-sheet poster categories. Another new feature was the increase in the number of these billboards. Also apparent was the sudden affluence of the new owners of the companies, who were top Nigerian managers who had taken over ownership of the indigenization policy.

2.1.3 The Glorious Tomorrow

The prediction of Akinbobola, (1996 p.8) he asserts that "I have peeped into the future and seen a glorious tomorrow Outdoor advertising" cannot be truer than what is presently prevalent in the Outdoor advertising industry.

2.1.4 Outdoor Advertising Modernization

As the entire globe experiences changes in the different aspects of it's business and life, every part of the facets of each economy also had its forms of one transformation of the other. Given the need to spread tentacles to every region of Nigeria, Outdoor practitioners launched regional offices in different parts of the country. This era is characterized by the introduction of new technology into the practice of Outdoor media and advertising in general. The new phase of Outdoor advertising and introduction of modern billboards have also come with their own challenges. Amal (2014) confirmed that Nigerian Outdoor market constitutes $80 \%$ of sales in terms of newly produced board annually.

\subsection{Characteristics of Outdoor Advertising}

Outdoor advertising, regardless of its diversity, has some qualities and features which are common to all. According to Daramola (2016), the following are universal characteristics of Outdoor advertising media.

Mobile Audience: The target of all Outdoor advertising is the mobile audience which includes commuters, motorists, pedestrians, and so on. Consequently, they have little or no time to peruse the Outdoor advertising messages.

Out-of-home or Outdoor displays: Most Outdoor advertising media are physically located Outdoor of the building. Nonetheless, some are situated inside large structures such as stadia, theatres, mass transit terminuses and vehicles, air and sea ports, motor parks.

Passing Images/shadow: Since the audience is on the move and has its mind focused on their respective destinations, they can only afford a momentary or passing glance or feeble attention for the Outdoor advertising.

Largest Advertising Media: In terms of physical size or lengths, breadth and height, Outdoor advertising 
media generally surpass other media such as newspaper, magazine, radio, and television.

The area with High Pedestrian or Vehicle Traffic: Outdoor advertising displays are usually located in places with a large concentration of pedestrian, commuters, and motorists. From the viewpoint of pedestrians, Outdoor advertisings are physically located in places around open markets and shopping malls as well as motor and car parks, stadia and theatres.

Free for the Audience: Exposure to Outdoor advertising does not attract any financial cost or obligation from the audience. Perhaps, it is the unsuspecting audience or public that needs to be protected from unscrupulous and questionable Outdoor advertisement. Little wonder restrictions are placed on the Outdoor advertisements of products such as tobacco and liquor in places such as educational institutions, hospital, and place of religious worship such as churches, mosques and synagogues.

Costly to the Advertiser: All forms of Outdoor advertising are inevitably more or less costly to the advertiser depending on the location, material as well as local regulations. From the viewpoint of the advertising agency, there is a specific monthly/ yearly rent attached to all billboards in all location. In more specific terms, the expenses of Outdoor advertising include, but not limited to the cost of materials, workmanship, printing, transportation, land or site and taxes.

Illuminated Outdoor adds visibility and glamour at night: When an Outdoor advertisement is illuminated at night, it extends the exposure time, creates visibility and beautifies the physical environment.

\subsection{Outdoor Advertising and its Environmental Impacts}

Olaghere (1997) contends that Outdoor advertising is anything with the objective of persuading and influencing people who are outside or Outdoor. Despite the various advantages, strength and contribution of Outdoor advertising to the global economy, the environmental challenges that come with it leaves little to be desired. The environment represents man's totality because man's existence is dependent on it. Therefore, there is no doubt that if the modern man with his daily technological inventions and landmark scientific discoveries is to live peacefully and in harmony with other man and with nature, there is need to take the issues of the environment seriously. Examining Outdoor advertising, safety of highway users and the environment involve identifying how the Outdoor advertising industry negatively affects the environment in the following ways: Clustering of billboard, placement of billboards in places that affect traffic flow, erection of billboards in unhygienic/unfriendly/unapproved places, erection of billboards in places that obstruct free flow of drainages, erection of environmentally unfriendly billboards, and falling billboards constitute nuisance on the roads and to the environment.

\subsection{Technology and the Outdoor}

Technology is a common feature in every facet of our lives and has made the process of communication and advertising easy. The advent of new media (internet) has revolutionized the process of information dissemination to "pin down" the buyer that is most likely to be receptive to particular product or service has given the time and space. It is a fact that technology has finally caught up with the world's oldest advertising medium, while Outdoor advertising has received much attention in the light of various technologies driven solutions that are being implemented to acquire data that will put advertising at par with the other media. Through the use of bar code technology, operational efficiency is being improved; this allows outdoor companies to immediately inform advertisers when messages are installed. Digital billboards that can instantly adjust their messages to the passing audience are popping up every day in cities across Nigeria. Also in the country are "sound enabled billboards" that are equipped with a motion-sensitive infrared device that can launch a recorded message or jingle lauding the sponsor of the billboard; all are technological advancements that have already been tested and applied. It is, therefore, logical to infer that the role of technology further compounded the impact of Outdoor advertising on highway users.

\subsection{Theoretical Framework}

This paper is hinged on Klapper's Phenomenistic Theory. The theory states that media rarely have any direct effects and are relatively powerless when compared to other social and psychological factors (Baran and Davis, 2012). The main assumption of this model is that mass media messages do not provide sufficient effects on its own but through certain mediating factors which render mass communication a contributing agent in the process of reinforcing the existing condition in the audience and not the sole cause of such reinforcement. Selectivity is the strategy employed by the selective influence theory to determine the impact of communication messages. Applying this theory to the study, every highway users subject every billboard advertising messages to the following selective processes: Selective exposure, selective perception, selective attention and selective retention.

Selective Exposure: This presupposes that people expose themselves to those communication messages that are in agreement with their existing attitude (belief) and avoid those that are not.

Selective Attention: This is the idea that because people cannot possibly attend to all competing media 
messages, they pay attention to those parts of a message that is inconsonant with their view, attitudes, and beliefs.

Selective Perception: According to Burgoon and Ruffner (1978), perception is the process of making sense out of an experience. Selective perception, therefore, explains individual processing of the media messages subsequent to attention and exposure. It is the state of cognitive organization of information, cognitive interpretation, comprehension and assignment of meaning.

Selective Retention: The principle of selective retention refers to the human ability to remember or retain information or messages favourable or consistent with one's belief, attitude and ideas. Based on this theory, the researcher predicts that Outdoor advertising messages are not only retained but also have an impact on the safety of highway users.

\subsection{Empirical Review of Extant Studies}

Outdoor advertising is basically intended to capture the attention of road users. Mostly, these advertisements are billboards that road users can see while they drive, ride, or walk on public roads, and that promote a product, event or activity. It could be that due to particular features of these billboards (e.g. size, moving images, luminance, content, et cetera) they capture so much attention of the highway users that they impede the safe defending driving.

Vlakveld and Helman (2019) carried out a survey, lasting a period of two years assessing the distraction of vehicle drivers in Europe from Roadside Technology-based Signage. An adapted version of the SEEV (Salience, Effort, Expectancy, Value) framework about visual attention of road users was used to structure their findings. The factor of 'Luminance' was added to the SEEV-framework and the existing factor of 'Value' was expanded. These changes were made, respectively, to ensure that the issues of glare and billboard content were considered along with salience, the effort required from drivers, and the impact of expectancy. Fifty studies were identified about the effects of roadside advertisements on crash risk or road user behaviour. Forty-nine of these studies were about drivers and one was about motorcyclists. The authors affirmed that five of the studies there are relationships between crashes and roadside advertisements. Although the results are inconclusive; for instance, in one of the study an increase in the number of crashes was found near billboards but in the four other studies, there was no correlation. Hence, according to the authors, it is very difficult to assess the effect of billboards on crash risk. One issue is the lack of statistical power; because crashes are rare events and the stretches of road in which a billboard could contribute to a crash are short, the included number of crashes was mostly small.

Another issue as reported by Vlakveld and Helman (2019) is the research design. Three of the five studies were before-and-after-studies (comparing the crash rate before the placement of billboards and the crash rate after the placement of billboards) and in two studies a comparison site was also included. A before-and-afterstudy with a comparison site is a stronger research design than a before-and-after-study without such a group. There were two studies with sufficient statistical power and a comparison site. In one of them an increase of crashes near billboards was found, but not in the other. The authors concluded that given this, studies that focus on behaviour and driving behaviour are the best available to make an assessment of the safety of billboards.

Oviedo-Trespalacios, Truelove, Watson \& Hinton (2019) study focused on the impact of roadside advertising signs on driver behaviour and road safety. To examine this, a theory-driven systematic literature review was undertaken. In total, 90 unique documents were identified and reviewed using the Task-Capability Interface (TCI) Model to explain the potential safety impact of roadside advertising. The findings confirmed that the TCI model is a useful tool for describing the relationship between roadside advertising and drivers' behaviour. From this perspective, roadside advertising signs can be considered environmental clutter, which adds additional demands to the driving task. In particular, roadside advertising signs impaired eye movement patterns of drivers. Additionally, it was demonstrated that the impact of roadside advertising on driving behaviour is greatly moderated by individual differences among drivers.

Of great importance was that young drivers invest more attentional resources in interacting with roadside advertising, which suggests a lower capacity to discriminate between relevant and irrelevant driving information. Based on the available evidence, however, the authors opine that it is not possible to definitively conclude that there is a direct relationship between the driving behaviour changes attributed to roadside advertising and road crashes. Nonetheless, while most studies remain inconclusive, there is an emerging trend in the literature suggesting that roadside advertising can increase crash risk, particularly for those signs that have the capacity to frequently change (often referred to as digital billboards). Lastly, it is important to mention that most of the empirical studies undertaken to date feature strong methodological limitations. Consequently, there is an urgent need for more research in this area, given that roadside technology and the transport system are changing rapidly.

The study of Belyusar, Reimer, Mehler, and Coughlin (2016) examined The impact of digital billboards on driver safety. The authors investigate glances and vehicle control while driving past a digital billboard on the highway; compare behaviour when drivers passed the same double-sided billboard in two directions; show increased number and duration of glances toward the billboard regardless of direction and Glances off-road and toward the billboard significantly increase in its presence. The Results show a significant shift in the number and 
length of glances toward the billboards and an increased percentage of time glancing off the road in their presence. Findings were particularly evident at the time the billboards transitioned between advertisements. Since rapidly changing stimuli are difficult to ignore, the planned increase in episodically changing digital displays near the roadway may be argued to be a potential safety concern, the authors concluded.

The study of Meetiyagoda (2016) was concerned with the Intrusiveness of Outdoor Advertising and Visual Information. According to the author, the placement of outdoor advertising is a crucial task where people identify roadside adverts that are as intrusive elements of the built environment. Hence, the study examined why outdoor advertisements are considered as intrusive elements. This research aims to examine an association between the level of intrusiveness (a negative visual quality) and the level of visual information. The methodology used includes Shannon's Information Theory-based entropy values to measure the level of visual information and the level of intrusiveness is evaluated by conducting a perception survey. The result of the level of visual information is correlated with the road users' perception to see the association; using the t-test, the result shows that the outdoor advertising add visual information to the built environment and the correlation analysis depicts a positive correlation between the level of visual information and intrusiveness. Moreover, this research introduces a widely applicable methodology that proves the possibility of employing entropy to measure the visual information and permits advertisers and planners to objectively decide the placement or elimination of outdoor advertising.

Also important to this paper was the study carried out by Mrgole (2000). The study provides a review of current research on driver distraction, focusing on outdoor advertising. It also examined to what degree, these degradations in driving performance translate into a decreased road safety. Megole observed that the disorderliness of the driver during driving can be divided into four basic groups: visual disturbances; The driver does not look at driving directions, hearing impairment; The driver is disturbed by a sound that does not pay attention to the current traffic situation, hand interference; The driver does not use both hands for steering with a steering wheel and a cognitive disorder; Not the driver's focus and indecision. Roadside advertising is intended to attract the driver's attention, which at a given moment reduces the driver's attention to the actual traffic situation and driving. A driver's disturbance may also be caused by roadside advertising in the event of a strong luminance of the advertised screens, talking about the blindness of the driver or in case of motion. The study concluded by provides a possible proposal for the regulation of roadside advertising in such a way that it is not a disturbance of the driver or a possible non-visualization of vertical signalization.

\section{Methodology}

This study adopts a quantitative survey research method. Sobowale (2008) maintained that "the survey technique is the most commonly used by behavioural scientists". This approach was used to elicit responses from selected respondents on the subject matter.

\subsection{Population of Study}

To obtain the participants' responses, the researcher used a random sample of commuters, motorists and other highway users who are regular travellers on Lagos and Abeokuta roads given the metropolitan nature of Lagos State and new look Ogun State is wearing in recent years. George, (2014) underscored the choice of Lagos as the population of study when he said at the 2014 African Outdoor Advertising Conference and Exhibition that Lagos takes about $60 \%$ of the nation's Out-of-Home Advertising Industry, with 146 registered out-of-home Advertising Companies and being the commercial nerves centre of the nation. A total of one hundred (100) respondents were obtained for this study. Billboard types of use for these study were static and digital billboards along Lagos and Abeokuta roads

\subsection{Data Collection}

The research instrument used under the survey method was the questionnaire. The Likert Scale Questions type of questionnaires, where respondents were asked to strongly agree, agree, no idea, strongly disagree and disagree with statements and questions were used. The research instrument was designed to have a set of questions that helped the researcher accomplished the research objectives.

\subsection{Data Presentation and Analysis}

The demographic characteristics of the respondents were presented in simple descriptive statistics while quantitative data generated were analysed in the table using Statistical Product and Service Solutions (SPSS) 21; while linear regression was used to test the hypotheses. Of the 100 copies of the questionnaire administered, 97 copies were validly collected and used. 


\section{Presentation of Findings}

Figure 1: Demographic Profile of respondents

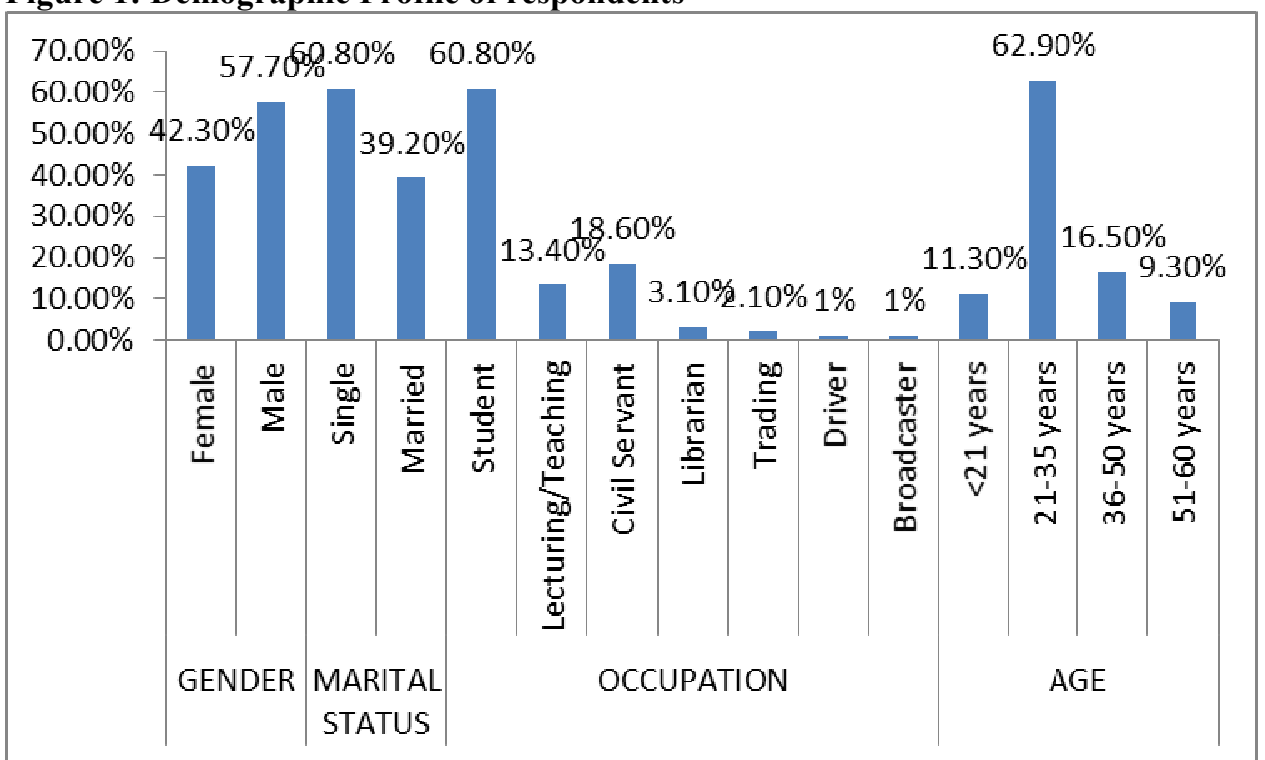

Figure 1 reveals the gender, age, marital status and occupation of the respondents. It shows that $42.3 \%$ of the respondents were female while $57.7 \%$ were male of the 97 valid respondents. This is supported by the research findings in the literature which states that we have more men behind the wheel than women. The marital status of the respondents revealed that of the total respondents, $60.8 \%$ were single while 39.2 were married. It also revealed that $62.9 \%$ of the respondents fell within the age ranged of $21-35$ years, $16.5 \%$ fell within the age range of $36-50$ years, $11.3 \%$ fall within the age range of $18-21$, while the remaining $9 \%$ fell within the range of 51-65years. Figure 1 further shows the occupation of the respondents, $60.8 \%$ were students, $13.4 \%$ were into lecturing/teaching, Civil servant stood at $18.6 \%$, librarian $3.1 \%$, trading, drivers and broadcasters are $2.1 \%, 1 \%$ and $1 \%$ respectively

Table 1

Respondents who drove a car and those who did not

\begin{tabular}{|c|c|c|c|c|c|}
\hline & & Frequency & Percent & Valid Percent & $\begin{array}{l}\text { Cumulative } \\
\text { Percent }\end{array}$ \\
\hline Valid & Yes & 56 & 57.7 & 57.7 & 57.7 \\
\hline & No & 41 & 42.3 & 42.3 & 100.0 \\
\hline & Total & 97 & 100.0 & 100.0 & Total \\
\hline
\end{tabular}

The table above shows that $57.7 \%$ of the respondents drove a vehicle while $42.3 \%$ did not drive a car; however, these respondents who did not drive a car qualified as road users as identified in the population of the study.

Research Question One: Is Outdoor advertising a distraction to highway users?

Table $2 \mathrm{a}$

Billboards distracting in general

\begin{tabular}{|l|l|l|l|l|l|}
\hline \multicolumn{2}{|c|}{} & Frequency & Percent & Valid Percent & $\begin{array}{l}\text { Cumulative } \\
\text { Percent }\end{array}$ \\
\hline \multirow{5}{*}{ Valid } & Strongly Agreed & 21 & 21.6 & 21.6 & 21.6 \\
\cline { 2 - 6 } & Agreed & 27 & 27.8 & 27.8 & 49.5 \\
\cline { 2 - 6 } & No Idea & 3 & 3.1 & 3.1 & 52.6 \\
\cline { 2 - 6 } & Strongly disagreed & 12 & 12.4 & 12.4 & 64.9 \\
\cline { 2 - 6 } & Disagreed & 34 & 35.1 & 35.1 & 100.0 \\
\cline { 2 - 6 } & Total & 97 & 100.0 & 100.0 & \\
\hline
\end{tabular}


Table $2 b$

Are you more likely to read a message on the billboard either electronic or static one

\begin{tabular}{|l|l|l|l|l|l|}
\hline \multicolumn{2}{|c|}{} & Frequency & Percent & Valid Percent & $\begin{array}{l}\text { Cumulative } \\
\text { Percent }\end{array}$ \\
\hline \multirow{3}{*}{ Valid } & Strongly Agreed & 35 & 36.1 & 36.1 & 36.1 \\
\cline { 2 - 6 } & Agreed & 47 & 48.5 & 48.5 & 84.5 \\
\cline { 2 - 6 } & No Idea & 4 & 4.1 & 4.1 & 88.7 \\
\cline { 2 - 6 } & Strongly disagreed & 3 & 3.1 & 3.1 & 91.8 \\
\cline { 2 - 6 } & Disagreed & 8 & 8.2 & 8.2 & 100.0 \\
\cline { 2 - 6 } & Total & 97 & 100.0 & 100.0 & \\
\hline
\end{tabular}

$48.4 \%$ respondents strongly agreed and agreed with the statement that Outdoor advertising actually distracts highway users while $47.5 \%$ strongly disagreed and disagreed that outdoor billboard distract highway users. This result indicates that to a large extent billboards constitute a level of distraction to highway users. The respondents that disagreed with this statement cannot be pushed aside given $0.9 \%$ difference between the agreed and disagreed. The facts that Table $3 \mathrm{~b}$ recorded $84.5 \%$ of respondents who strongly agreed and agreed and $11.3 \%$ strongly disagreed and disagreed to the statement that road users are more likely to read a message on the billboard either electronic or static one is an indication that billboards distract. This result supports the position of Copeland (2010) that DBBs flash images on a single board (every four to ten seconds) can advertise to far more clients than a traditional board, making them an attractive advertisement option.

Research Question 2: Do Outdoor advertising impact negatively on safety of the highway users?

Table $3 \mathrm{a}$

\begin{tabular}{|l|l|l|l|l|l|}
\hline \multicolumn{2}{|c|}{ Outdoor advertising contributes to road accidents on highways } \\
\hline \multirow{3}{*}{} & Frequency & Percent & Valid Percent & $\begin{array}{l}\text { Cumulative } \\
\text { Percent }\end{array}$ \\
\hline \multirow{5}{*}{ Valid } & Strongly Agreed & 5 & 5.2 & 5.2 & 5.2 \\
\cline { 2 - 6 } & Agreed & 30 & 30.9 & 30.9 & 36.1 \\
\cline { 2 - 6 } & No Idea & 16 & 16.5 & 16.5 & 52.6 \\
\cline { 2 - 6 } & Strongly disagreed & 12 & 12.4 & 12.4 & 64.9 \\
\cline { 2 - 6 } & Disagreed & 34 & 35.1 & 35.1 & 100.0 \\
\cline { 2 - 6 } & Total & 97 & 100.0 & 100.0 & \\
\hline
\end{tabular}

Figure $3 \mathrm{~b}$

Outdoor Advertising reduces visibility of motorists on the highway

\begin{tabular}{|l|l|l|l|l|l|}
\hline \multicolumn{2}{|c|}{} & Frequency & Percent & Valid Percent & $\begin{array}{l}\text { Cumulative } \\
\text { Percent }\end{array}$ \\
\hline \multirow{5}{*}{ Valid } & Strongly Agreed & 7 & 7.2 & 7.2 & 7.2 \\
\cline { 2 - 6 } & Agreed & 15 & 15.5 & 15.5 & 22.7 \\
\cline { 2 - 6 } & No Idea & 11 & 11.3 & 11.3 & 34.0 \\
\cline { 2 - 6 } & Strongly disagreed & 14 & 14.4 & 14.4 & 48.5 \\
\cline { 2 - 6 } & Disagreed & 50 & 51.5 & 51.5 & 100.0 \\
\cline { 2 - 6 } & Total & 97 & 100.0 & 100.0 & \\
\hline
\end{tabular}

The respondents in Table $3 \mathrm{a}$ who strongly agreed and agreed that Outdoor advertising contributes to a road accident on highways are $5(5.2 \%)$ and $30(30.9 \%)$ respectively while $11.3 \%$ of the respondents could not decide whether Outdoor advertising contributes to a road accident on the highway. $65.9 \%$ strongly disagreed and disagreed to the statement. Similarly, Table $4 \mathrm{~b}$ also follows the trend. $22.7 \%$ of respondents strongly agreed and agreed with the statement that Outdoor advertising reduces the visibility of motorist on the highway. $65.9 \%$ of respondents strongly disagreed and disagreed respectively, while $11.3 \%$ of respondents were neutral. It could be inferred from Tables $4 \mathrm{a}$ and $4 \mathrm{~b}$ that Outdoor advertising neither contributes to road accidents nor reduces the visibility of motorists on the highway. This result underscores the effort being made by Lagos State advertising and signage Agency at ensuring sanity and compliance with the relevant regulations. 
Research Question 3: Do Outdoor advertising constitutes environmental nuisance?

Table 5

Outdoor advertising constitutes environmental nuisance on highways

\begin{tabular}{|l|l|l|l|l|l|}
\hline \multicolumn{2}{|c|}{} & Frequency & Percent & Valid Percent & $\begin{array}{l}\text { Cumulative } \\
\text { Percent }\end{array}$ \\
\hline \multirow{5}{*}{ Valid } & Strongly Agreed & 4 & 4.1 & 4.1 & 4.1 \\
\cline { 2 - 6 } & Agreed & 19 & 19.6 & 19.6 & 23.7 \\
\cline { 2 - 6 } & No Idea & 9 & 9.3 & 9.3 & 33.0 \\
\cline { 2 - 6 } & Strongly disagreed & 17 & 17.5 & 17.5 & 50.5 \\
\cline { 2 - 6 } & Disagreed & 48 & 49.5 & 49.5 & 100.0 \\
\cline { 2 - 6 } & Total & 97 & 100.0 & 100.0 & \\
\hline
\end{tabular}

$23.7 \%$ of the respondents strongly agreed and agreed that Outdoor advertising constitutes environmental nuisance on the highway while $67 \%$ strongly disagreed and disagreed with the statement. $9.3 \%$ stayed neutral on the issue. As identified by Akinbobola's (1996) maintains that Outdoor advertising is in its glorious era. From this submission, this study concludes that this era is characterized by the introduction of new technology into the practice of Outdoor media and advertising in general. Consequently, this trend explains various acts of indiscipline among the operators.

\subsection{Test of Hypothesis}

$\mathbf{H}_{1}$ : Outdoor advertising significantly distracts the highway users

Table 6

Chi-Square Tests

\begin{tabular}{|l|l|l|l|}
\hline & Value & df & $\begin{array}{l}\text { Asymp. Sig. (2- } \\
\text { sided) }\end{array}$ \\
\hline Pearson Chi-Square & $10.831^{\mathrm{a}}$ & 12 & .543 \\
\hline Likelihood Ratio & 11.289 & 12 & .504 \\
\hline Linear-by-Linear Association & .480 & 1 & .489 \\
\hline N of Valid Cases & 97 & & \\
\hline
\end{tabular}

Hypothesis two was also tested using chi-square which yielded a P-value of .480 which is higher than the 0.05 significance. This value suggests no significant relationship; hence, hypothesis two is rejected, meaning that Outdoor advertising does not distract the highway users.

$\mathbf{H}_{2}$ : Outdoor advertising significantly influence accident on the highway.

Table 7

\section{Chi-Square Tests}

\begin{tabular}{|l|l|l|l|}
\hline & Value & Df & $\begin{array}{l}\text { Asymp. Sig. (2- } \\
\text { sided) }\end{array}$ \\
\hline Pearson Chi-Square & $6.989^{\mathrm{a}}$ & 12 & .858 \\
\hline Likelihood Ratio & 8.166 & 12 & .772 \\
\hline Linear-by-Linear Association & .185 & 1 & .667 \\
\hline N of Valid Cases & 97 & & \\
\hline
\end{tabular}

In Table 7, the result from the analysis indicates no significant relationship as the p-value stood at $\mathbf{. 1 8 5}$ meaning that the alternate hypothesis states that Outdoor advertising significantly influence accident on the highway is rejected.

$\mathbf{H}_{3}$ : Outdoor advertising significantly constitutes environmental nuisance

Table 8

\section{Chi-Square Tests}

\begin{tabular}{|l|l|l|l|}
\hline & Value & Df & $\begin{array}{l}\text { Asymp. Sig. (2- } \\
\text { sided) }\end{array}$ \\
\hline Pearson Chi-Square & $10.157^{\mathrm{a}}$ & 12 & .602 \\
\hline Likelihood Ratio & 12.176 & 12 & .432 \\
\hline Linear-by-Linear Association & .434 & 1 & .510 \\
\hline N of Valid Cases & 97 & & \\
\hline
\end{tabular}

The chi-square $\mathrm{x}^{2}$ test which yielded a $\mathrm{p}$-value of $\mathbf{. 4 3 4}$ shows no strong significance between Outdoor advertising and environmental nuisance. Therefore, the hypothesis that Outdoor advertising significantly 
constitutes environmental nuisance is rejected.

\section{Discussion of Findings}

From the data analyzed, it is evident that Outdoor advertising does not have a major negative influence on the safety of highway users. Despite this result, it is important to note that, the percentages of respondents that are of the opinion that Outdoor advertising distracts and contributes to road accidents must not be totally ignored. Darren (2017) affirms this position that Outdoor advertising is not only one of the oldest media of advertising in the world, but has one purpose and one purpose only: to distract drivers. Collaborating Darren's position, (Sisiopiku, Jones, Sullivan, Patharka, and Tang, 2013), opines that targeted messages that promote interactivity with the road users are particularly troublesome as they are hypothesized to be distracting to the driver and other road users.

The result from this study shows that Outdoor advertising has come of age and its impact is massive. The three hypotheses hypothesized by the researcher, 1. Outdoor advertising significantly distracts the highway users, 2. Outdoor advertising significantly influences safety on the highway and 3. Outdoor advertising significantly constitutes an environmental nuisance, were all rejected. This could be inferred to be the "glorious tomorrow" Akinbobola prophesized about; a period when advertising is being handled by professionals in terms of contents and positioning, thus solving the problem of distractions of highway users. The implication of the rejection of Outdoor advertising significantly constitutes environmental nuisance is that contrarily Outdoor advertising beautifies the environment as against constituting an environmental nuisance. Oviedo-Trespalacios et al (2019) study supported the fact that outdoor advertising can be considered environmental clutter, which adds additional demands to the driving task. The authors concluded that roadside advertising signs impaired eye movement patterns of drivers. However, the outcome of this study underscored the assertion of (Copeland, 2010) that because DBBs flash images every four to ten seconds, a single board can advertise too far more clients than a traditional board, making them attractive advertisement options. The consequence of this, the introduction of Digital Billboards beautifies the environment. This conclusion is at variance to Belyusar et al (2016) position on DBB when they argued that rapidly changing stimuli in changing digital billboard displayed near the roadway may be are difficult to ignore by the highway users and a potential safety concern.

\subsection{Conclusion and Recommendations}

In light of the findings, the study concludes that Outdoor advertising does not impact negatively on the safety of highway users. This study also found out that although Outdoor advertising is distracting, is an effective medium of advertising, which influences highway users to purchase products advertised on billboards Outdoor. To this end, it is important for both practitioners and the regulatory agencies to ensure compliance with the rule of best practices which is globally accepted.

For the advertisers, this study has further proved that Outdoor advertising is an effective medium they could exploit, but this contradicts the position of Aroloye (1997) who viewed Outdoor advertising as a lesser medium that advertisers should use. The highway users are, therefore, counselled to be focused and concentrate, while using the road to avoid any mishaps on the highway.

\section{References}

Akinbobola, F.B., (1996) Outdoor Advertising: Yesterday and Today: Paper presented at OAAN seminar Amal, O.. (2014). Lassa, African Sign Expo. Published in Daily Trust Newspaper, July 27, 2004.

Aroloye, A.A., (1997). Outdoor Advertising in Nigeria. Unpublished Post-Graduate Diploma in Mass Communication Thesis, UNILAG

Baran, S. J \& Davis, D. K. (2012) Mass communication theory: Foundations, ferment, and future. belmont, calif: APA (6th ed.) Wadsworth Pub. Co. (1995).

Belyusar, D., Reimer, B., Mehler, B., Coughlin, J.F., 2016. A field study on the effects of digital billboards on glance behavior during highway driving. Accid. Anal. Prev. 88, 88-96

Burgoon, M. \& Ruffer M. (1978). Human Communication: A communication model of personal space violations: explication and an initial test. Publisher: Holt Rinehart and Winston, 1978. Pp. 129-142 https://doi.org/10.1111/j.1468-2958.1978.tb00603.x

Copeland, (2010). Predicting the future technology is atricky Business. Publisher: tech/product news and review. https://arstechnica.com

Daramola, A.C. (2010). Principle and practice of professional advertising: A multinational and comparative analysis vol. 1: advertising and allied disciplines, Lagos: certified marketing communication institute of Nigeria (CMCIN)

Daramola, A. C., (2016). Nigerian Outdoor advertising: Issues and trends (Unpublished Article) edited by Daramola A. C., \& Tejumola J. A.

Darren, C., (2017). Does roadside advertising distract drivers? 2017 driving tests resources, PO Box 90411, 
Victoria Street West, Auckland, 1142, New Zeala

George, N., (2014). Lassa, African Sign Expo. Published in Daily Trust Newspaper, July 27, 2004.

Jefkins, F., (1992). Public Relation. Estover, Plymouth, McDonald and Evans

Kother, P. (1990). Marketing Management. Published: Publi Union https://www.abebooks.com/book.../marketing-management/.../philip.../sr.../20000007.

Meetiyagoda, Lakshika. (2016). Intrusiveness of Outdoor Advertising and Visual Information. International Journal of Advanced Engineering, Management and Science. 2. 2127-2135.

Mrgole, A.L. (2000). The Influence on Road Safety Due to Driver Distraction from Outdoor Advertising: Case Study. American Scientific Research Journal for Engineering, Technology, and Sciences (ASRJETS)ISSN (Print) 2313-4410, ISSN (Online) 2313-4402@ Global Society of Scientific Research and Researchers http://asrjetsjournal.org/

Olaghere, S. E. (1998). Outdoor and the environment: The role of the Outdoor advertising operators, Paper presented at OAAN workshop.

Osunbiyi, Bidemi., (1999). Advertisng principle and practice. Publisher: Gbenga Gbesan Associates, Abeokuta.

Oviedo-Trespalacios, O., \& Truelove, V., Watson, B., \& Hinton, J. (2019). The impact of road advertising signs on driver behaviour and implications for road safety: A critical systematic review. Transportation Research Part A Policy and Practice. 122. 85-98. 10.1016/j.tra.2019.01.012.Outdoor Advertising Association of America [OAAA] (2013). Out of home media formats. http://www.oaaa.org/OutofHomeAdvertising/OOHMediaFormats/OOHMediaFormats.aspx

Sobowale, I., (2008), Scientific journalism. What tools for precision journalist: John West Publication, Lagos.

Sisiopiku, V. P., Mozahidul, M. I., Wittig, S., Welburn, S. C., \& Despina, S. (2014). Civil, Construction, and Environmental Engineering; ${ }^{\text {Psychology }}$. University of Alabama at Birmingham Birmingham, AL, 35294, USA

Sisiopiku, V. P. (2014). Proceedings of the 5th International Conference on Applied Human Factors and Ergonomics AHFE, Kraków, Poland Pp. 19-23 July 2014 Edited by T. Ahram, W. Karwowski and T. Marek

Vlakveld, W. \& Helman, S. (2019). Assessing Distraction of Vehicle drivers in Europe from Roadside Technology-based Signage. CEDR Call 2016: Safety. PEB Project Contact: Des O'Connor (Transport Infrastructure Ireland)

Wirsig, C. R. and Leonard, C. M (1987). Terminal nerve damage impairs the mating behaviour of male hamter brain res., 417: 293-303. 